\title{
Development and evaluation of a serological test for diagnosis of COVID-19 with selected recombinant spike proteins
}

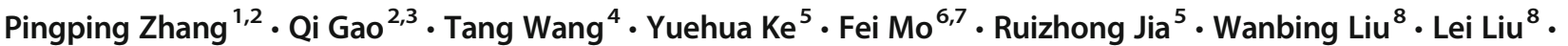

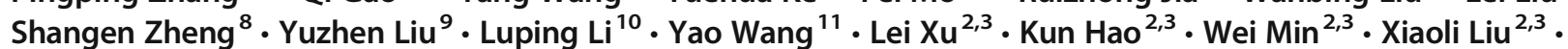 \\ Ruifu Yang ${ }^{1,2} \cdot$ Shiyue $\mathrm{Li}^{4}$. Changqing Lin ${ }^{2,3}$. Yong Zhao ${ }^{1,2}$
}

Received: 13 July 2020 / Accepted: 5 November 2020 / Published online: 12 November 2020

(C) Springer-Verlag GmbH Germany, part of Springer Nature 2020

\begin{abstract}
Serological test is a valuable diagnostic tool for coronavirus disease 2019 (COVID-19). However, considerable improvements to these tests are needed, especially in the detection sensitivity. In this study, six recombinant nucleocapsid and spike proteins of severe acute respiratory syndrome coronavirus 2 (SARS-CoV-2) were prepared and evaluated, including three prokaryotic expression nucleocapsid proteins $(\mathrm{rN}, \mathrm{rN} 1, \mathrm{rN} 2)$ and three eukaryotic expression spike proteins (rS1, rS-RBD, rS-RBD-mFc). The recombinant proteins with the highest ELISA titers ( $\mathrm{rS} 1$ and $\mathrm{rS}-\mathrm{RBD}-\mathrm{mFc}$ ) were selected to develop a double-antigen sandwich colloidal gold immunochromatography assay (GICA) to detect total antibodies against SARS-CoV-2. The clinical evaluation results showed that the sensitivity and specificity of GICA were $92.09 \%$ (419/455) and 99.44\% (706/710), respectively. Moreover, a significant number $(65.63 \%, 21 / 32)$ of COVID-19 patients with undetectable viral RNA were correctly diagnosed by the GICA method. In conclusion, the eukaryotic expression spike proteins (rS1 and rS-RBD-mFc) are more suitable than the prokaryotic expression nucleocapsid proteins for serological diagnosis of SARS-CoV-2. The proposed GICA for detection of total antibodies could be a powerful complement to the current RNA tests for COVID-19.
\end{abstract}

Keywords SARS-CoV-2 $\cdot$ Recombinant protein $\cdot$ Serological diagnosis $\cdot$ Colloidal gold immunochromatography assay (GICA)

Pingping Zhang, Qi Gao and Tang Wang contributed equally to this work.

Ruifu Yang is a senior author

Shiyue Li

1sywhd@sina.com

Changqing Lin

changqing.lin@hotgen.com.cn

Yong Zhao

zhaoyong179@139.com

1 State Key Laboratory of Pathogen and Biosecurity, Beijing Institute of Microbiology and Epidemiology, Beijing 100071, People's Republic of China

2 Beijing Key Laboratory of POCT for Bioemergency and Clinic, Beijing 100071, People's Republic of China

3 Beijing Hotgen Biotechnology Inc., Beijing 102600, People's Republic of China

4 Wuhan University School of Health Sciences, Wuhan 430071, People's Republic of China

5 Huoshenshan Hospital, Wuhan 430101, People's Republic of China

6 Center for Clinical Laboratories, Affiliated Hospital of Guizhou Medical University, Guiyang 550004, People's Republic of China

7 Department of Basic Clinical Laboratory Medicine, School of Clinical Laboratory Science, Guizhou Medical University, Guiyang 550004, People's Republic of China

8 General Hospital of Central Theater Command of the PLA, Wuhan 430070, People's Republic of China

$9 \quad$ Shijiazhuang Fifth Hospital, Shijiazhuang 050023, People's Republic of China

10 The Sixth People's Hospital of Shenyang, Shenyang 110006, People's Republic of China

11 Department of Clinical Laboratory, Peking Union Medical College Hospital, Peking Union Medical College, Chinese Academy of Medical Sciences, Beijing 100032, People's Republic of China 


\section{Introduction}

Coronavirus disease 2019 (COVID-19) caused by the severe acute respiratory syndrome coronavirus-2 (SARS-CoV-2) poses a huge threat to global public health. Early diagnosis is essentially important for the disease control and clinical treatment. However, the current nucleic acid testing for SARS-CoV-2 carries a negligible false-negative risk [1, 2]. Serological tests are considered to be a powerful complement to the nucleic acid tests, especially for COVID-19 patients with undetectable viral RNA [3]. Among the serological tests, colloidal gold immunochromatography assay (GICA) is a simple and rapid test method, suitable for timely diagnosis and large-scale screening of COVID-19 patients. Most GICA tests are developed based on indirect or capture immunoassay, by using SARS-CoV-2-related recombinant antigen and secondary antibodies to detect $\mathrm{IgM} / \mathrm{IgG}$ antibodies against SARS-CoV-2 in patient sera. However, these GICA approaches usually have no ideal detection sensitivity; the pooled sensitivity for SARS-CoV-2 was $66.0 \%$ (49.3\% to 79.3\%) according to previous reports [4-6]. A recent study showed that the sensitivity of the total antibody (IgM, IgG, $\operatorname{IgA}$, etc.) test is higher than that of the single IgM or IgG test, which was developed based on the enzyme-linked immunosorbent assay (ELISA) in double-antigen sandwich format [7]. This format can also be applied into GICA and is expected to improve the detection sensitivity.

To develop a reliable double-antigen sandwich GICA, it is important to obtain suitable SARS-CoV-2 antigens or related recombinant proteins. SARS-CoV-2 is a $\beta$ family coronavirus, including the spike (S) protein, envelope $(\mathrm{E})$ protein, membrane $(\mathrm{M})$ protein, and nucleocapsid $(\mathrm{N})$ protein. Among them, the $\mathrm{N}$ protein is the most abundant, relatively conservative protein in coronaviruses; thus, it is often used as a diagnostic antigen [8]. Our previous study showed that the antigenicity of the $\mathrm{COOH}$ terminus is higher than that of the $\mathrm{NH}_{2}$ terminus in the $\mathrm{N}$ protein of SARS-CoV; and the former $\mathrm{N}$ protein fragment may have the same antigenicity with the full-length $\mathrm{N}$ protein [9]. The S protein is the common target when designing vaccines based on neutralizing antibodies. It contains a receptor binding domain (S-RBD) in the S1 subunit, which mediates receptor binding and membrane fusion $[10,11]$. According to report, the S-RBD of SARS-CoV-2 has higher affinity for angiotensin-converting enzyme 2 (ACE2) than SARS-CoV and lacks cross-reactivity with monoclonal antibodies against S-RBD of SARS-CoV [12], indicating the potential diagnostic value of $\mathrm{S}$ protein.

In the present study, we prepared six recombinant proteins based on the reported SARS-CoV-2 sequence (GenBank accession MN908947) [13]. Three recombinant $\mathrm{N}$ proteins were obtained by prokaryotic expression, including the full-length recombinant $\mathrm{N}$ protein $(\mathrm{rN}), \mathrm{NH}_{2}$ terminal $(\mathrm{rN} 1)$ protein fragments, and $\mathrm{COOH}$ terminal (rN2) fragments from this protein.
Three recombinant $\mathrm{S}$ proteins were obtained by eukaryotic expression, including an $\mathrm{S} 1$ domain $(\mathrm{rS} 1)$ fragment, the receptor binding domain (rS-RBD), and S-RBD ligated to the Fc fragment from mouse (rS-RBD-mFc). The recombinant proteins were evaluated using indirect ELISA. Two recombinant proteins with the highest ELISA titers (rS1and rS-RBD-mFc) were chosen to develop a double-antigen sandwich GICA to detect total antibodies against SARS-CoV-2. Performance of the GICA method was evaluated with 1165 clinical samples, which showed a high detection sensitivity $(92.09 \%)$ and good specificity (99.44\%). Moreover, 65.6\% (21/32) of COVID-19 patients with undetectable viral RNA were correctly diagnosed by the GICA method.

The results indicate that the proposed GICA test can serve as a reliable complement to current RNA tests for COVID-19.

\section{Material and methods}

\section{Materials}

DNA polymerase $(2 \times$ Pfu MasterMix $)$ was purchased from Beijing TransGen Biotech (Beijing, China). T4 DNA ligase and Gibson Assembly kit were from New England BioLabs Inc., (Ipswich, England). Eukaryotic vectors $\mathrm{H} 293$ and $\mathrm{H} 293-\mathrm{Fc}$, which were used for transient expression, were obtained from the Laboratory of Protein Project, Beijing Institute of Biotechnology, China. FreeStyle ${ }^{\mathrm{TM}} 293$ expression medium, Opti$\mathrm{MEM}^{\circledR} \mathrm{I}(1 \times)$, a reduced serum medium, and 293 fectin $^{\mathrm{TM}}$ reagents were purchased from Invitrogen Inc. (CA, Carlsbad, USA). The Unique CDSystem for protein purification was from Suzhou Inscinstech Co., Ltd. (Suzhou, China). The DNA extraction/purification kit was from Beijing TransGen Biotech. Primer construction and sequencing work were conducted by Beijing Tianyi Huiyuan Biotech Ltd. and Beijing Biomed Biotech Ltd., respectively. GICA nitrocellulose (NC) membranes were obtained from Millipore Sigma (Saint Louis, MO, USA); glass fiber and absorbent pads were from Shanghai Kinbio Tech. Co., Ltd. (Shanghai, China).

The gene sequences of the recombinant proteins were all derived from the RNA sequence of SARS-CoV-2 strain from Wuhan (GenBank accession MN908947). The nucleotide positions of the gene sequences are rS1 (21602-23584), rS-RBD (22514-23311), rN (28274-29530), rN1 (28274-28900), and rN2 (28901-29530). The N, N1, and N2 gene cloning vectors were constructed by General Biosystems Co., Ltd. (Anhui, China). The S1 DNA sequence was optimized and synthesized by GenScript Co., Ltd. (Nanjing, China). The vector and bacterial strains for prokaryotic expression were pET28a, E. coli Rosetta, or BL21 (DE3). 


\section{Preparation of the recombinant S proteins}

The full coding region, which was obtained by overlapping extension PCR using primers containing restriction enzyme recognition sites (Supplementary Table 1), was ligated to HEK293 vectors after digestion. The recombinant plasmids were transformed into $E$. coli $\mathrm{DH} 5 \alpha$, and bacterial colonies were selected on Luria-Bertani (LB) agar containing ampicillin. Positive colonies were cultured in $500 \mu \mathrm{L}$ LB liquid medium for 2-4 h, and the resultant plasmids were extracted, PCR-verified, and sequenced. Positive recombinant plasmids $(210 \mu \mathrm{g}$ each $)$ and liposomes $(280 \mu \mathrm{L})$ were diluted in $7 \mathrm{~mL}$ of opti-MEM medium for $5 \mathrm{~min}$, respectively, and mixed for 30 min, and H293 cells $\left(1.2 \times 10^{6} / \mathrm{mL}\right)$ were added. After culturing (120 rpm, $37^{\circ} \mathrm{C}$ with $5 \% \mathrm{CO}_{2}, 3-4$ days), the cell supernatants collected by centrifugation were purified with a $0.44-\mu \mathrm{m}$ filter and the Unique CDSystem chromatography workstation. After column protein A balancing (10 column volumes) with phosphate-buffered saline (PBS), the cell supernatants were placed under a flow rate of $2.0 \mathrm{~mL} / \mathrm{min}$ and then washed and eluted with PBS (five column volumes) and citric acid buffer ( $\mathrm{pH} 3.0$ ) to collect the purified protein. For desalination, a 1/3 sample volume was applied to a G25 column pre-balanced with PBS (5 column volumes), and each protein was collected after column washes with PBS. Their purities were confirmed by sodium dodecyl sulfatepolyacrylamide gel electrophoresis (SDS-PAGE).

\section{Preparation of the recombinant $\mathrm{N}$ proteins}

The N protein's full coding region was PCR amplified using primers containing restriction enzyme recognition sites (Supplementary Table 1). The restricted amplicons were ligated into pET28a or pET32a using T4 DNA ligase. The recombinant plasmids were transformed into E. coli Rosetta or BL21 (DE3), and the bacterial colonies were selected on LB agar containing kanamycin. Recombinant plasmids in the bacterial colonies were extracted and confirmed as authentic by DNA sequencing. Protein expression was induced for $5 \mathrm{~h}$ in positive bacterial colonies with $0.5 \mathrm{mM}$ isopropyl-Dthiogalactopyranoside (IPTG) at a starting optical density (OD) of 0.6. After centrifugation, the supernatants and precipitation products from the lysed bacteria were analyzed by SDS-PAGE. The rN, rN1, and rN2 recombinant proteins were produced by the bacteria harboring the recombinant plasmids via IPTG induction in $2 \mathrm{~L}$ of LB medium $\left(20^{\circ} \mathrm{C}, 200 \times g, 10 \mathrm{~h}\right)$, and the bacteria were harvested and lysed by ultrasonication $(300 \mathrm{~W}, 30 \mathrm{~min})$. The supernatants were clarified by centrifugation $(10,000 \times g, 20 \mathrm{~min})$, filtrated $(0.4-\mu \mathrm{m}$ filter membrane $)$ and run through a $3 \mathrm{~mL}$ Ni Sepharose column with $30 \mathrm{~mL}$ lysis buffer, and then washed extensively with
PBS containing imidazole (20-80 $\mathrm{mM}$ gradient) to remove non-specific proteins. The target proteins were eluted with PBS containing $250 \mathrm{mM}$ imidazole.

\section{Preliminary evaluation of the recombinant proteins by ELISA}

The recombinant proteins were initially evaluated by indirect ELISA. After coating the wells with the prepared recombinant proteins, $50 \mu \mathrm{L}$ of serially diluted human samples was added to the wells and mixed with $50 \mu \mathrm{L}$ of horseradish peroxidase (HRP)-labeled goat anti-human $\operatorname{IgM}$ or $\operatorname{IgG}$, followed by incubation $\left(37^{\circ} \mathrm{C}, 60 \mathrm{~min}\right)$. After the solution was removed and the wells had been washed with PBS buffer containing Tween-20 five times, $50 \mu \mathrm{L}$ of tetramethylbenzidine substrate was added to the wells in the plate for $15 \mathrm{~min}$. OD values were measured on a microplate reader $(450 / 630 \mathrm{~nm})$, and recombinant proteins with high OD values for COVID-19 patient sera and low OD reads for the negative control sera were used for all further experiments.

ELISA plates coated with the six recombinant proteins were first tested with seven negative sera from healthy people. Their average values plus twofold standard deviations (mean $+2 \mathrm{SD}$ ) were used as the cutoffs. However, they were not completely equivalent for each protein and some were set at 0.2 when the calculated values were below 0.2. Sera from two patients with COVID-19 were diluted at ratios of 1:800, 1:400, and 1:100 for IgM detection and ratios of 1:80, 1:40, and 1:20 for IgG detection. The average value (mean) from the negative serum samples was set as the background value, and the lowest antibody titer with a value higher than the cutoff was set as the sensitivity level.

\section{Preparation of the GICA strip with selected recombinant proteins}

Colloidal gold suspension was prepared by reducing gold chloride with citrate. The colloidal gold was conjugated to recombinant protein $\mathrm{rS}-\mathrm{RBD}$. Briefly, $1 \mathrm{mg}$ of $\mathrm{rS}-\mathrm{RBD}$ was added to $100 \mathrm{~mL}$ of the colloidal gold suspension. After a 30min reaction, conjugation was blocked using $10 \mathrm{~mL}$ of $10 \%$ bovine serum albumin (BSA) for $15 \mathrm{~min}$. The colloidal gold conjugate collected (centrifugation at 12,000 rpm, $30 \mathrm{~min}$, and $4{ }^{\circ} \mathrm{C}$ ) was resuspended in PBS containing $0.1 \%$ BSA and $0.1 \%$ Tween-20.

The colloidal gold and rS-RBD $(0.5 \mathrm{mg} / \mathrm{mL})$ conjugate was applied to a conjugate pad (glass fiber) $(30 \mu \mathrm{L} / \mathrm{cm}$, dried at $37^{\circ} \mathrm{C}, 3 \mathrm{~h}$ ). Using a dispenser (XYZ3000; BioDot, Irvine, $\mathrm{CA}), \mathrm{rS} 1$ and the secondary polyclonal antibody $(2 \mathrm{mg} / \mathrm{mL})$ were coated onto the nitrocellulose membrane as the test and control lines, respectively, at a dispensing rate of $1.0 \mu \mathrm{L} / \mathrm{cm}$. The membrane was then dried at $37^{\circ} \mathrm{C}$ for $1 \mathrm{~h}$. Finally, the 
nitrocellulose membrane, conjugate pad, sample pad, and the absorbent pads were assembled and cut into 4-mm strips.

\section{Performance evaluation of the GICA test}

Positive sera from a COVID-19 patient in the early phase $(<$ 7 days after symptom onset) was collected and diluted with running buffer at a ratio of 1:10-1:320. The limit of detection of the GICA strip was determined using $100 \mu \mathrm{L}$ of the sample, and $0.9 \% \mathrm{NaCl}$ was used as the blank control. The results could be obtained by naked eyes after $5-10 \mathrm{~min}$. Each test was repeated three times. Additionally, 41 samples collected from healthy men were tested to preliminarily evaluate the false-positive rate of the GICA method.

\section{Clinical evaluation of the GICA test}

A multi-center prospective clinical evaluation was conducted to evaluate performances of the GICA test. The GICA test was evaluated with 1165 serum samples, of which 455 samples were from confirmed COVID-19 patients according to The Diagnosis and Treatment Protocol for COVID-19 (7th edition) in China and 710 samples from healthy people. All the samples were collected from Huoshenshan Hospital, General Hospital of Central Theater Command of the PLA, the Sixth People's Hospital of Shenyang, Peking Union Medical College Hospital, and Shijiazhuang Fifth Hospital in China. In addition, 32 serum samples from suspected cases with negative RNA test results were collected from the abovementioned hospitals while the clinical symptom and computed tomography (CT) image changes of typical viral pneumonia were observed for these patients. All samples were tested with the GICA strips, and nucleic acid detection by officially approved RNA test kits was used as control. The Ct cutoff values for positivity of RNA tests were determined according to the kits and real-time PCR machines used in each hospital. In addition, double-antigen sandwich-based ELISA kits (Hotgen Biotech, Beijing, China) for the detection of total antibodies against SARS-CoV-2 were also used as a comparison.

\section{Results}

\section{Acquisition of the six recombinant proteins}

Through gene subcloning by overlapping extension PCR and ligation to the HEK 293 vector, the S1, S-RBD-mFc (containing the mouse $\mathrm{Fc}$ fragment), and S-RBD recombinant plasmids were constructed and verified by PCR and sequencing (Supplementary Fig. 1). Following lipofection, transient expression in eukaryotic HEK293 cells, and protein purification, highly pure $\mathrm{rS} 1, \mathrm{rS}-\mathrm{RBD}-\mathrm{mFc}$, and $\mathrm{rS}-\mathrm{RBD}$ were obtained.
Through gene subcloning and ligation to the pET vector, recombinant $\mathrm{N}, \mathrm{N} 1$, and $\mathrm{N} 2$ plasmids were constructed and verified by PCR and sequencing (Supplementary Fig. 1). The rN, rN1, and rN2 expression products from IPTG induction at $37{ }^{\circ} \mathrm{C}$ in E. coli were identified in the culture supernatants and in the precipitates, so the induction temperature was lowered to $20{ }^{\circ} \mathrm{C}$, which increased the protein in the supernatants significantly. The supernatant proteins were purified and used for subsequent studies. That the SARSCoV-2 $\mathrm{N}$ proteins were present in the precipitates implies that their expression in E. coli may influence their accurate folding or conformation, because the viral $\mathrm{N}$ protein may be conformationally modified after transcription in human cells. Overall, six high-yield recombinant proteins from SARS-CoV-2 with high purities were obtained, as summarized in Table 1.

\section{Preliminary ELISA evaluation of the recombinant proteins}

Indirect ELISAs were used to preliminarily evaluate the six recombinant proteins. Using serum samples from seven healthy people as the negative controls, serial samples from two patients in the early phase ( $<7$ days after symptom onset) of COVID-19 were detected. For the S proteins, the coefficient of variation $(\mathrm{CV})$ for the seven negative samples was 20-30\%. For the N proteins, the CV was $74-92 \%$, resulting in a high cutoff value.

For IgM detection, all the $\mathrm{S}$ proteins had lower background values and higher $\mathrm{OD}$ values than those of the $\mathrm{N}$ proteins, as well as higher sensitivities (1:800) (Fig. 1). For IgG detection, rS-RBD-mFc had the highest sensitivity $(1: 80)$, while the second highest sensitivity $(1: 40)$ was attained by rS1, rS-RBD, and rN (Fig. 1). Although with the same sensitivity and similar background, rS1 produced a higher OD value than rS-RBD. The better performance of $\mathrm{rS}-\mathrm{RBD}-\mathrm{mFc}$ when compared with rS-RBD may be related to the protein $\mathrm{Fc}$ fragments, which can increase the half-life and stability for the RBD protein fragment from the $\mathrm{S}$ protein. Overall, $\mathrm{rS}-\mathrm{RBD}-\mathrm{mFc}$ and $\mathrm{rS} 1$ were best suited for IgM and $\operatorname{IgG}$ detection.

The IgM-specific sensitivities for ELISA (from 1:100 to 1:800) are all higher than those for $\operatorname{IgG}(1: 20-1: 80)$, mostly because the positive serum samples came from patients during the early phase of COVID-19 infection. Additionally, the antigenicity of full-length $\mathrm{rN}$ was higher than that of fragments $\mathrm{rN} 1$ and $\mathrm{rN} 2$, which is consistent with the findings from our previous study on SARS-CoV [9]. However, the higher sensitivity of rN1 over rN2 suggests that the antigenicity of the protein fragment at the $\mathrm{NH}_{2}$ terminus of the $\mathrm{N}$ protein was higher than that at the $\mathrm{COOH}$ terminus, which is the opposite result of our previous study on SARS-CoV [9]. 
Table 1 Information of the prepared recombinant proteins

\begin{tabular}{lllllll}
\hline Recombinant protein & Tag $^{\mathrm{a}}$ & Amino acid & $\mathrm{MW}^{\mathrm{b}}(\mathrm{kDa})$ & Expression & Strain $^{\mathrm{c}}$ & Restriction site $^{\mathrm{d}}$ \\
\hline rS1-His & His & 667 & 76.5 & Eukaryotic & HEK 293 & EcoR I/BamH I \\
rS-RBD-mFc & His & 501 & 63 & Eukaryotic & HEK 293 & Afl II/Nhe I \\
rS-RBD & His & 259 & 30 & Eukaryotic & HEK 293 & Afl II/BamH I \\
rN & His & 428 & 45 & Prokaryotic (pET28a) & E. coli Rosetta & NcoI/XhoI \\
rN1 & Sumo, His & 273 & 47 & Prokaryotic (pET28a) & E. coli BL21 & BamHI/HindIII \\
rN2 & TrxA, His & 210 & 43 & Prokaryotic (pET32a) & E. coli BL21 & NcoI/XhoI \\
\hline
\end{tabular}

${ }^{\text {a }}$ Protein tags. Sumo and TrxA tags are 18 and $20 \mathrm{kDa}$, respectively

${ }^{\mathrm{b}}$ Molecular weight of the recombinant protein including the tags

${ }^{\mathrm{c}}$ Strains used for engineering and protein expression

${ }^{\mathrm{d}}$ Restriction enzyme recognition sites

\section{Evaluation of the recombinant proteins by GICA tests}

A double-antigen sandwich GICA test was developed using the recombinant $\mathrm{rS}-\mathrm{RBD}-\mathrm{mFc}$ and $\mathrm{rS} 1$ proteins, which can be used to detect total antibodies against SARS-CoV-2 in serum samples (Fig. 2). Serial dilutions of a serum sample from a COVID-19 patient in the early phase were tested by the GICA test. It showed that a positive result was observed at a 1:160 dilution
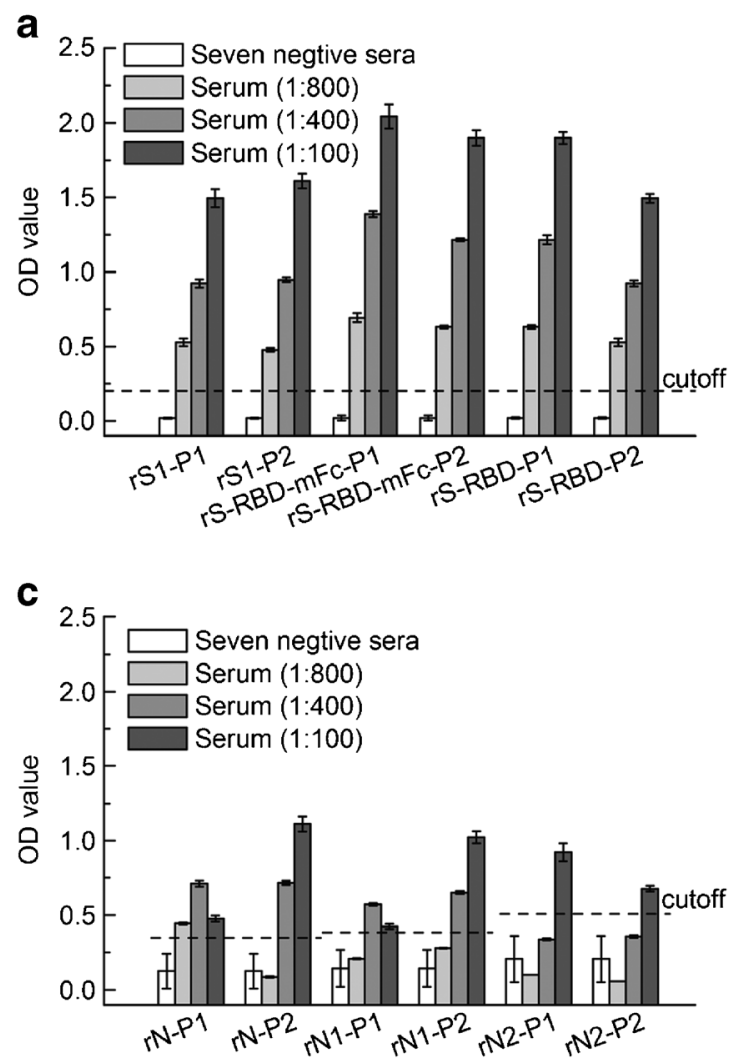

(Fig. 2), indicating the GICA method was able to detect low-titer antibodies in serum. Moreover, several samples from patients infected with influenza A, influenza B, respiratory syncytial virus, Mycoplasma pneumoniae, and Chlamydia pneumoniae were all tested by the GICA test (Fig. 2). No cross-reaction was observed with these samples. In addition, there was no false-positive result when testing 41 serum samples from healthy people.
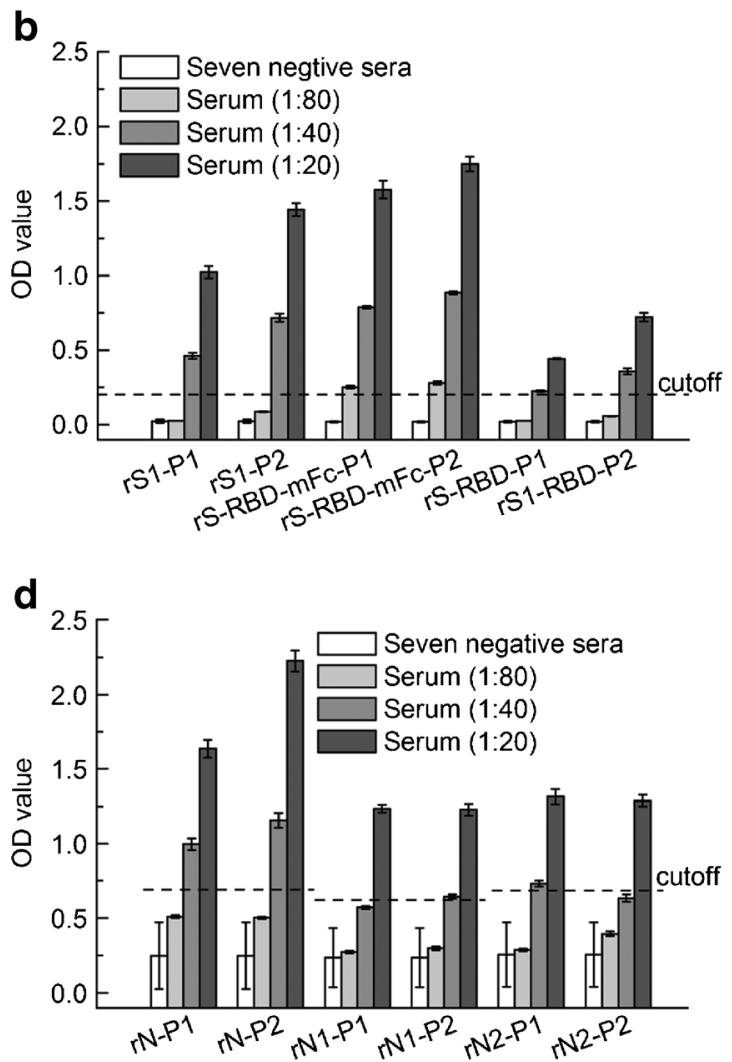

Fig. 1 Evaluation of the recombinant $\mathrm{S}$ and $\mathrm{N}$ proteins by indirect IgM-ELISA (a, c) and IgG-ELISA (b, d), respectively, with serum samples from seven healthy people and two COVID-19 patients (P1 and P2). Dashed lines refer to the cutoff values 
Fig. 2 Schematic illustration (a), lower detection limit (b), and selectivity (c) of the sandwichformat GICA strip for total antibody detection against SARSCoV-2

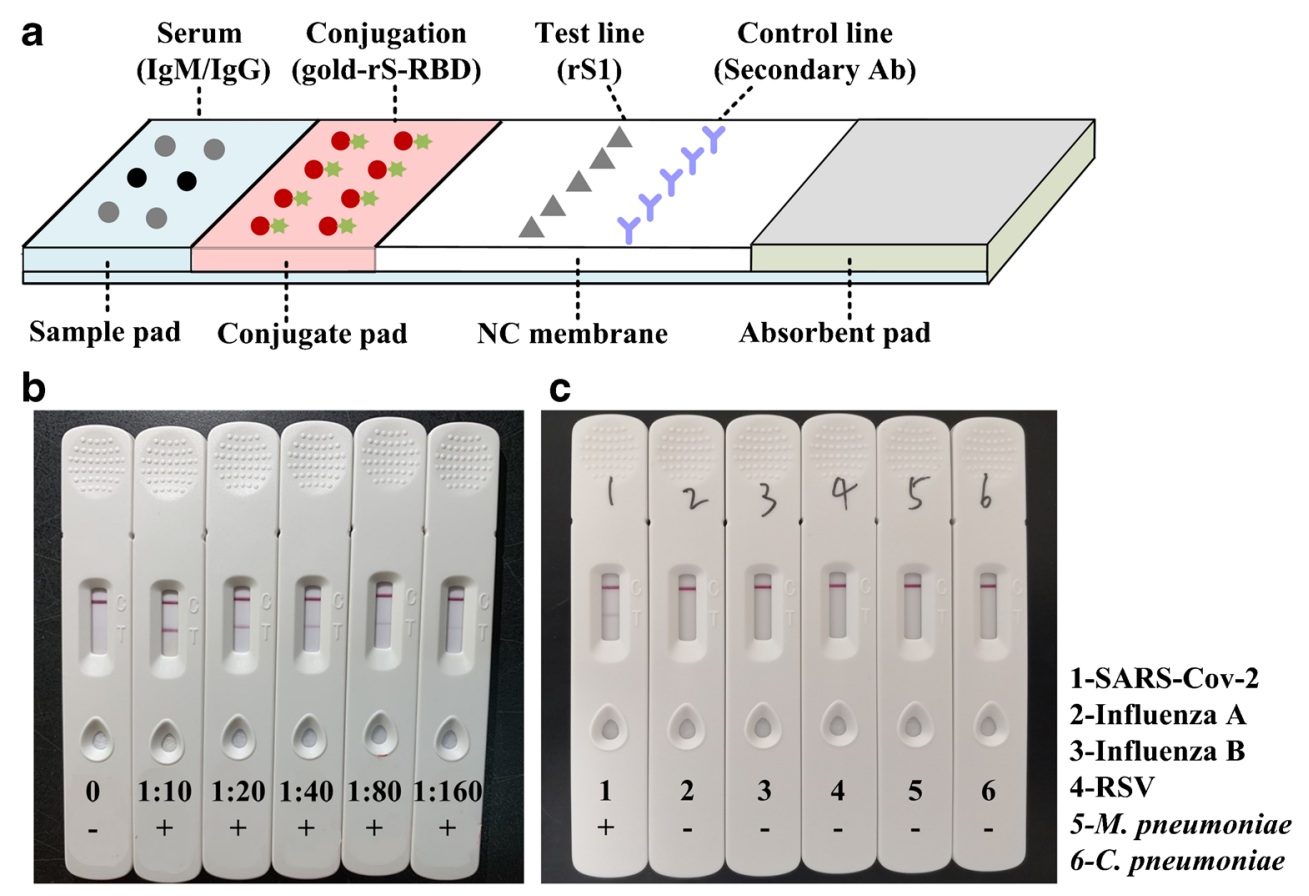

\section{Clinical evaluation of the GICA test}

Altogether, 1165 serum samples from healthy people and confirmed cases of COVID-19 were tested by the GICA method. As shown in Table 2, the detection sensitivity and specificity of GICA were $92.09 \%$ (419/455) and 99.44\% (706/710), respectively. The overall accuracy is $96.57 \%(1125 / 1165)$, demonstrating reliability of the GICA test. In addition, 32 serum samples from suspected cases were collected and tested by the GICA test. All these samples were from patients that have clinical symptoms and CT changes of typical viral pneumonia, but the RNA test results are all negative. Among these samples, $65.63 \%$ (21/32) were detectable by the GICA method. Detailed clinical information of the 32 cases is provided in Supplementary Table 2. This result indicates that the GICA test for detection of total antibodies against SARS-CoV-2 could be used as a powerful complement to the nucleic acid tests, especially for COVID-19 patients with undetectable viral RNA.
The 455 confirmed cases out of the 1165 cases were divided into three groups according to the days of symptom onset (Table 3). For the group of patients in the early phase $(\leq$ 7 days), the GICA test presented a lower detection rate $(46.8 \%, 22 / 47)$ than that of the RNA test $(85.1 \%, 40 / 47)$. However, the detection rate of the GICA test increased to $83.6 \%(51 / 61)$ and up to $99.7 \%$ (346/347) for patients in the middle and late phases ( $>7$ days), which is comparable to that of the RNA test. The result was supposed to be reasonable, because specific antibodies were commonly produced in humans after about $7-10$ days of infection and could maintain for several months. Therefore, the GICA test is more suitable for COVID-19 patients in the middle and late phases.

In addition, a total of 251 cases were tested by both the GICA method and a double-antigen sandwich ELISA method during the clinical evaluation. The ELISA kit was developed based on the same recombinant spike proteins that are used in the GICA test. The results showed that the two methods displayed a high consistency (kappa $=0.919, p<0.001)$
Table 2 Clinical evaluation performances of the GICA method

\begin{tabular}{|c|c|c|c|c|c|}
\hline \multirow[t]{2}{*}{ Groups } & & \multicolumn{2}{|c|}{ GICA detection results } & \multirow[t]{2}{*}{ In total } & \multirow[t]{2}{*}{ Detection rate $(\%)$} \\
\hline & & $\mathrm{P}$ & $\mathrm{N}$ & & \\
\hline \multirow[t]{3}{*}{ Clinically confirmed } & $\mathrm{P}$ & 419 & 36 & 455 & 92.09 \\
\hline & $\mathrm{N}$ & 4 & 706 & 710 & 99.44 \\
\hline & In total & 423 & 742 & 1165 & 96.57 \\
\hline
\end{tabular}

P: the number of positive cases

$\mathrm{N}$ : the number of negative cases 
Table 3 Comparisons of the detection rates of GICA test and RNA test for COVID-19 patients in different phases (days after symptom onset)

\begin{tabular}{llll}
\hline Groups & Clinical confirmed cases & RNA-positive cases & GICA-positive cases \\
\hline $1-7$ days & 47 & $40(85.1 \%)$ & $22(46.8 \%)$ \\
$8-14$ days & 61 & $47(77.0 \%)$ & $51(83.6 \%)$ \\
$>14$ days & 347 & $330(95.1 \%)$ & $346(99.7 \%)$ \\
In total & 455 & $417(91.6 \%)$ & $419(92.1 \%)$ \\
\hline
\end{tabular}

(Supplementary Table 3). And they have comparable detection sensitivity and specificity (Table 4). Both the sensitivities are $88.9 \%$ (64/72); the specificity of the GICA test and ELISA is $97.8 \%(175 / 179)$ and $98.9 \%$ (177/179), respectively.

\section{Discussion}

Rapid and accurate detection methods are urgently required for the diagnosis of patients infected with SARS-CoV-2 [14, 15]. However, the current RNA tests depend on whether there is a sufficient viral load in the patient's upper respiratory tract and reasonable sample quality, leading to a significant number of false-negative results. Consequently, serological tests, along with the epidemic history, clinical symptoms, and image features of chest CT, should be taken into consideration for the diagnosis of COVID-19 [16, 17]. In this study, the GICA test showed a high sensitivity $(92.09 \%, 419 / 455)$ and specificity $(99.44 \%, 706 / 710)$, and a significant number $(65.63 \%, 21 / 32)$ of COVID-19 patients with undetectable viral RNA were correctly detected by the GICA method, indicating the diagnostic value of serological testing for COVID-19.

Selecting suitable SARS-CoV-2-related recombinant proteins is essential for developing a reliable serological test. In the study, we prepared six recombinant proteins, including three $\mathrm{S}$ proteins (rS1, rS-RBD, rS-RBD-mFc) and three $\mathrm{N}$ proteins $(\mathrm{rN}, \mathrm{rN} 1, \mathrm{rN} 2)$. Preliminary evaluation by indirect ELISA revealed that the three $\mathrm{S}$ proteins were more suitable for developing serological tests than the three $\mathrm{N}$ proteins. However, the antigenicity of $\mathrm{S}$ proteins and that of the $\mathrm{N}$ proteins could not be confirmed in this study, because the two recombinant proteins are prepared using different protein expression systems. The $\mathrm{N}$ protein with high content and

Table 4 Clinical performances of the GICA and ELISA methods

\begin{tabular}{|c|c|c|c|c|c|c|}
\hline \multirow[t]{2}{*}{ Groups } & & \multicolumn{2}{|c|}{ ELISA } & \multicolumn{2}{|c|}{ GICA } & \multirow[t]{2}{*}{ In tota } \\
\hline & & $\mathrm{P}$ & $\mathrm{N}$ & $\mathrm{P}$ & $\mathrm{N}$ & \\
\hline \multirow[t]{3}{*}{ Clinical confirmed } & $\mathrm{P}$ & 64 & 8 & 64 & 8 & 72 \\
\hline & $\mathrm{N}$ & 2 & 177 & 4 & 175 & 179 \\
\hline & In total & 66 & 185 & 68 & 183 & 251 \\
\hline
\end{tabular}

$\mathrm{P}$ : the number of positive cases

$\mathrm{N}$ : the number of negative cases strong immunogenicity is a main structural protein of SARS-CoV-2. It can be efficiently expressed through a prokaryotic expression system and has good immunoreactivity. However, as a transmembrane protein with hydrophobic regions, the $\mathrm{S}$ protein is better prepared using a eukaryotic expression system, which can express proteins with complex structure and high biological activity. Although the supernatant of the prokaryotic expression recombinant $\mathrm{N}$ proteins was used in this study, insoluble precipitates were found during preparation, especially rN2, making it likely that some of their conformations were slightly different from the natural forms, or modifications for some sites were missing. Thus, the antigenicity of $\mathrm{N}$ protein should be studied after expression in a eukaryotic system in the future.

In conclusion, six recombinant proteins of SARS-CoV-2 were prepared and evaluated. It showed that the eukaryotic expression spike proteins are more suitable than the prokaryotic expression nucleocapsid proteins for the serological diagnosis of SARS-CoV-2 infections. A double-antigen sandwich GICA test was developed using the selected recombinant proteins ( $\mathrm{rS} 1$ and $\mathrm{rS}-\mathrm{RBD}-\mathrm{mFc}$ ), which can detect total antibodies against SARS-CoV-2 in human serum. Clinical evaluations of the GICA tests showed a high sensitivity and specificity comparable to those of the RNA tests. Given its simplicity, reliability, and cost-effectiveness, the GICA method could be used as a powerful complement to current COVID-19 diagnostic tools.

Supplementary Information The online version contains supplementary material available at https://doi.org/10.1007/s10096-020-04102-4.

Author contributions RY, PZ, YZ, CL, and SL designed the experiments. PZ, YZ, QG, TW, YK, FM, RJ, WL, LL, SZ, YL, LL, YW, $\mathrm{LX}, \mathrm{KH}, \mathrm{WM}$, and XL performed the experiments. RY, PZ, YZ, CL, and SL analyzed the data. RY, PZ, and YZ wrote the manuscript.

Funding This study was supported by the National Key Research and Development Program of China (Grant No. 2018YFC1200502 and No. 2019YFC1200603).

Data availability The datasets generated during and/or analyzed during the current study are available from the corresponding author on reasonable request.

\section{Compliance with ethical standards}

Conflict of interest The authors declare that they have no conflict of interest. 
Ethics approval This study was approved by the Medical Ethical Committee of Peking Union Medical College Hospital (approval number 002285), General Hospital of Central Theater Command of the PLA (approval number 2020-003-1), and Shijiazhuang Fifth Hospital (approval number 2020-002).

Consent to participate Informed consent was obtained from all individual participants included in the study.

Consent to publish Written informed consent for publication of their clinical details was obtained from the patient/parent/guardian/ relative of the patient.

\section{References}

1. Chu DKW, Pan Y, Cheng SMS, Hui KPY, Krishnan P, Liu Y, Ng DYM, Wan CKC, Yang P, Wang Q, Peiris M, Poon LLM (2020) Molecular diagnosis of a novel coronavirus (2019-nCoV) causing an outbreak of pneumonia. Clin Chem 66(4):549-555

2. Zhang W, Du RH, Li B, Zheng XS, Yang XL, Hu B, Wang YY, Xiao GF, Yan B, Shi ZL, Zhou P (2020) Molecular and serological investigation of 2019-nCoV infected patients: implication of multiple shedding routes. Emerg Microbes Infect 9(1):386-389

3. Huang C, Wang Y, Li X, Ren L, Zhao J, Hu Y, Zhang L, Fan G, Xu J, Gu X, Cheng Z, Yu T, Xia J, Wei Y, Wu W, Xie X, Yin W, Li H, Liu M, Xiao Y, Gao H, Guo L, Xie J, Wang G, Jiang R, Gao Z, Jin Q, Wang J, Cao B (2020) Clinical features of patients infected with 2019 novel coronavirus in Wuhan, China. Lancet 395(10223):497506

4. Li Z, Yi Y, Luo X, Xiong N, Liu Y, Li S, Sun R, Wang Y, Hu B, Chen W, Zhang Y, Wang J, Huang B, Lin Y, Yang J, Cai W, Wang X, Cheng J, Chen Z, Sun K, Pan W, Zhan Z, Chen L, Ye F (2020) Development and clinical application of a rapid $\operatorname{IgM}-\operatorname{IgG}$ combined antibody test for SARS-CoV-2 infection diagnosis. J Med Virol 92(9):1518-1524

5. Montesinos I, Gruson D, Kabamba B, Dahma H, Van den Wijngaert S, Reza S, Carbone V, Vandenberg O, Gulbis B, Wolff F, Rodriguez-Villalobos H (2020) Evaluation of two automated and three rapid lateral flow immunoassays for the detection of anti-SARS-CoV-2 antibodies. J Clin Virol 128:104413

6. Lisboa Bastos M, Tavaziva G, Abidi SK, Campbell JR, Haraoui LP, Johnston JC, Lan Z, Law S, MacLean E, Trajman A, Menzies D, Benedetti A, Ahmad Khan F (2020) Diagnostic accuracy of serological tests for covid-19: systematic review and meta-analysis. BMJ 370:m2516

7. Zhao J, Yuan Q, Wang H, Liu W, Liao X, Su Y, Wang X, Yuan J, Li T, Li J, Qian S, Hong C, Wang F, Liu Y, Wang Z, He Q, Li Z, He B, Zhang T, Fu Y, Ge S, Liu L, Zhang J, Xia N, Zhang Z (2020) Antibody responses to SARS-CoV-2 in patients with novel coronavirus disease 2019. Clin Infect Dis. https://doi.org/10.1093/ cid/ciaa344

8. Seo SH, Wang L, Smith R, Collisson EW (1997) The carboxylterminal 120-residue polypeptide of infectious bronchitis virus nucleocapsid induces cytotoxic T lymphocytes and protects chickens from acute infection. J Virol 71(10):7889-7894

9. Chen Z, Pei D, Jiang L, Song Y, Wang J, Wang H, Zhou D, Zhai J, Du Z, Li B, Qiu M, Han Y, Guo Z, Yang R (2004) Antigenicity analysis of different regions of the severe acute respiratory syndrome coronavirus nucleocapsid protein. Clin Chem 50(6):988995

10. Zhou P, Yang XL, Wang XG, Hu B, Zhang L, Zhang W, Si HR, Zhu Y, Li B, Huang CL, Chen HD, Chen J, Luo Y, Guo H, Jiang RD, Liu MQ, Chen Y, Shen XR, Wang X, Zheng XS, Zhao K, Chen QJ, Deng F, Liu LL, Yan B, Zhan FX, Wang YY, Xiao GF, Shi ZL (2020) A pneumonia outbreak associated with a new coronavirus of probable bat origin. Nature 579(7798):270-273

11. Lu R, Zhao X, Li J, Niu P, Yang B, Wu H, Wang W, Song H, Huang B, Zhu N, Bi Y, Ma X, Zhan F, Wang L, Hu T, Zhou H, Hu Z, Zhou W, Zhao L, Chen J, Meng Y, Wang J, Lin Y, Yuan J, Xie Z, Ma J, Liu WJ, Wang D, Xu W, Holmes EC, Gao GF, Wu G, Chen W, Shi W, Tan W (2020) Genomic characterisation and epidemiology of 2019 novel coronavirus: implications for virus origins and receptor binding. Lancet 395(10224):565-574

12. Wrapp D, Wang N, Corbett KS, Goldsmith JA, Hsieh CL, Abiona O, Graham BS, McLellan JS (2020) Cryo-EM structure of the 2019-nCoV spike in the prefusion conformation. Science 367(6483):1260-1263

13. Wu F, Zhao S, Yu B, Chen YM, Wang W, Song ZG, Hu Y, Tao ZW, Tian JH, Pei YY, Yuan ML, Zhang YL, Dai FH, Liu Y, Wang QM, Zheng JJ, Xu L, Holmes EC, Zhang YZ (2020) A new coronavirus associated with human respiratory disease in China. Nature 579(7798):265-269

14. Wang D, Hu B, Hu C, Zhu F, Liu X, Zhang J, Wang B, Xiang H, Cheng Z, Xiong Y, Zhao Y, Li Y, Wang X, Peng Z (2020) Clinical characteristics of 138 hospitalized patients with 2019 novel coronavirus-infected pneumonia in Wuhan, China. JAMA 323(11)

15. Bai Y, Yao L, Wei T, Tian F, Jin D-Y, Chen L, Wang M (2020) Presumed asymptomatic carrier transmission of COVID-19. JAMA 323(14)

16. Song C, Yang D, Lu Y (2020) A COVID-19 patient with seven consecutive false-negative rRT-PCR results from sputum specimens. Intern Emerg Med 15(5):871-874

17. Pan Y, Guan H, Zhou S, Wang Y, Li Q, Zhu T, Hu Q, Xia L (2020) Initial CT findings and temporal changes in patients with the novel coronavirus pneumonia (2019-nCoV): a study of 63 patients in Wuhan, China. Eur Radiol 30(6):3306-3309

Publisher's note Springer Nature remains neutral with regard to jurisdictional claims in published maps and institutional affiliations. 